\section{Prolonged Shipping and Fluctuating Temperatures Promote Gray Mold Development and Leaf Yellowing on Geranium Liners}

\author{
Nathan J. Jahnke ${ }^{1,3}$, John M. Dole ${ }^{1}$, and H. David Shew ${ }^{2}$
}

ADDITIONAL INDEX wORDs. air temperature, botrytis blight, Botrytis cinerea, Pelargonium $\times$ bortorum, rooted cuttings

Summary. Postharvest environments during storage and shipping are often conducive to plant stress and disease development. Liners of four cultivars of geraniums (Pelargonium $\times$ bortorum) were evaluated every 2 days for their susceptibility to gray mold (Botrytis cinerea) and leaf yellowing over an 8-day simulated shipping period at either constant air temperature of $15^{\circ} \mathrm{C}$ or variable air temperatures cycling every 24 hours between 10 and $30^{\circ} \mathrm{C}$. The latter treatment was created using air temperature logs of commercial liner shipments sent to five locations during Spring 2016 and Fall 2016. We sprayed a spore suspension of $2 \times 10^{4}$ or $2 \times 10^{6}$ to inoculate liners before they were subjected to the two temperature treatments. Disease ratings did not reach significant levels for the dry control until day 6 of storage. Regardless of the spore concentration, ratings were similar for inoculated cuttings. Independent of the storage temperature and spore concentration, liners developed minor lesions by day 2 of storage. Cultivars varied slightly in disease ratings, with Tango Dark Red being the most susceptible, followed by Patriot Bright Red, Patriot Rose Pink, and Americana Red. During the 8-day incubation period, 'Patriot Rose Pink' developed the most leaf yellowing compared with the other three cultivars. Liners that experienced variable air temperatures had marginal leaf yellowing by day 2 , and this yellowing increased throughout the experiment. Liners placed at $15{ }^{\circ} \mathrm{C}$ had $\approx \mathbf{5 0} \%$ less leaf yellowing compared with liners exposed to variable air temperatures until day 8, when leaf yellowing was similar between the two air temperature treatments. Disease caused by $B$. cinerea was avoided when simulated shipping was 2 days or fewer, and a stable air temperature of $15^{\circ} \mathrm{C}$ reduced leaf yellowing on geranium liners compared with variable air temperatures.

$\mathrm{P}$ ostharvest environments ideally preserve vegetative cutting and liner quality until planting, and this process includes storage and shipping. Unrooted cuttings experience two shipping periods before they are grown to a finished size. First, cuttings are typically imported by the United States from stock plant farms in Central America (Williams, 2006). Second, rooting stations receive the cuttings and grow them for a short period of time before shipping the rooted cuttings (liners) to growers who finish the crop for sale to the final consumer. During shipping,

This paper is a portion of a thesis submitted by Nathan J. Jahnke to fulfill a Master's of Science degree requirement.

${ }^{1}$ Department of Horticultural Science, North Carolina State University, 2721 Founders Drive, Raleigh, NC 27695-7609

${ }^{2}$ Department of Entomology and Plant Pathology, North Carolina State University, 100 Derieux Place, Raleigh, NC 27695-7609

${ }^{3}$ Corresponding author. E-mail: njjahnke@ncsu.edu

https://doi.org/10.21273/HORTTECH04149-18 plants are placed in dark conditions and may be subjected to unfavorable air temperatures, high humidity, ethylene, and pathogens. Under limited light, plants can experience reduced photosynthesis rates, low carbohydrate reserves, and physical damage (Arteca et al., 1996; Faust et al., 2011).

The geranium is one of the most important floriculture crops in the United States, but it is susceptible to a variety of postharvest problems (Gibson and Dole, 2006). At the wholesale level, sales of finished products produced from vegetative geranium cuttings are currently $\approx \$ 108.8$ million (U.S. Department of Agriculture, 2016). However, leaf yellowing is a common postshipping issue that can be caused by high air temperatures, ethylene exposure, and low carbohydrate levels (Purer and Mayak, 1988; Rapaka et al., 2008). Yellow leaves do not make liners unusable; however, growers will file a claim with their supplier and must often use extra labor to remove senescing leaves to avoid gray mold and botrytis blight caused by Botrytis cinerea (Elad et al., 2007; Faust et al., 2011). The expected loss incurred due to gray mold is likely close to 10\% (Hausbeck, 1990), which does not account for increased cutting production, shipping, and losses due to yellowing and ethylene damage. In addition, geraniums are one of many floriculture crops susceptible to $B$. cinerea that are being imported as unrooted cuttings from off-shore producers.

Cultural practices that reduce disease incidence and severity during stock plant production such as leaf removal, air circulation, reduction of leaf wetness, and fungicides are generally not applicable during shipping. Shipments of cuttings and liners can also be exposed to unfavorable air temperatures and prolonged high humidity if delays occur during transit or if growers do not stick cuttings on arrival. Optimum shipping durations last less than $48 \mathrm{~h}$ (A. Carlson, personal communication); however, shipping delays could increase the time by another 2 or $3 \mathrm{~d}$. Once plant material is boxed and shipped, neither the supplier nor the receiving grower has complete control over the conditions the plant materials may experience. Sirjusingh and Sutton (1996) reported that $B$. cinerea can infect geranium leaves after $4 \mathrm{~h}$ of leaf wetness. Generally, plants are shipped dry, but water film on leaves or condensation during shipping could promote spore germination and infection. Infection is more likely to occur if condensation forms during shipping

\begin{tabular}{llll}
\hline $\begin{array}{l}\text { Units } \\
\text { To convert U.S. to SI, } \\
\text { multiply by }\end{array}$ & U.S. unit & SI unit & $\begin{array}{l}\text { To convert SI to U.S., } \\
\text { multiply by }\end{array}$ \\
\hline 29,574 & $\mathrm{fl} \mathrm{oz}$ & $\mu \mathrm{L}$ & $3.3814 \times 10^{-5}$ \\
29.5735 & $\mathrm{fl} \mathrm{oz}$ & $\mathrm{mL}$ & 0.0338 \\
2.54 & inch $(\mathrm{es})$ & $\mathrm{cm}$ & 0.3937 \\
25.4 & inch $(\mathrm{es})$ & $\mathrm{mm}$ & 0.0394 \\
1 & $\mathrm{ppm}$ & $\mathrm{mg} \cdot \mathrm{L}^{-1}$ & 1 \\
$\left({ }^{\circ} \mathrm{F}-32\right) \div 1.8$ & ${ }^{\circ} \mathrm{F}$ & ${ }^{\circ} \mathrm{C}$ & $\left({ }^{\circ} \mathrm{C} \times 1.8\right)+32$
\end{tabular}


or if plants are packed with wet leaves. Young, actively growing $\approx 1$-weekold tissue on the apical portion of the cuttings is more susceptible than 4-week-old tissue (Sirjusingh and Sutton, 1996). With no complete genetic resistance or identified resistance genes in geraniums, and with the increased fungicide resistance in $B$. cinerea populations, growers are reliant on cultural practices and quantitative resistance (Fillinger and Walker, 2016). Uchneat et al. (1999) surveyed 45 cultivars of geraniums and found different levels of susceptibility to B. cinerea. Although Uchneat et al. (1999) studied the susceptibility of whole plants and detached leaves, no research has been performed regarding the development of gray mold on propagules such as unrooted cuttings and liners during postharvest environments.

The objectives of our study were to: 1) determine air temperature and relative humidity $(\mathrm{RH})$ conditions within boxes of commercial liner shipments and 2) evaluate the susceptibility of geranium liners to leaf yellowing and $B$. cinerea during simulated shipping. The information gathered will allow growers to better predict potential gray mold problems during the shipping of liners from the point of boxing at the supplier to unpacking at the grower.

\section{Materials and methods}

DETERMINATION OF AIR TEMPERATURE AND HUMIDITY OF LINER SHIPMENTS. Air temperature and $\mathrm{RH}$ data loggers (RHT10; Extech Instruments, Waltham, MA) were sent to a commercial grower (Lucas Greenhouses, Monroeville, NJ) for inclusion in a shipment of geranium liners to record air temperature and $\mathrm{RH}$ of liner shipments. Loggers were set to record both air temperature and $\mathrm{RH}$ every $5 \mathrm{~min}$ with an accuracy of \pm $1.0{ }^{\circ} \mathrm{C}$ and $\pm 3 \% \mathrm{RH}$. Liners were irrigated $24 \mathrm{~h}$ before boxing, and loggers were placed in boxes between 0745 and $1230 \mathrm{HR}$. One shipment was sent to a commercial grower in each of the following states: Washington (26 Apr. 2016), Wisconsin (11 Oct. 2016), North Carolina (11 Oct. 2016), and Oregon (6 Dec. 2016). When shipments were received by the respective growers, data loggers were returned to North Carolina State University with a form detailing the arrival time and the quality of liners. Air temperature and RH trends during shipping were used to define suitable air temperatures for the simulated shipment treatments that were used in the following experiment involving liners produced at North Carolina State University.

LINER CULTURE. Unrooted geranium cuttings of 'Americana Red', 'Patriot Bright Red', 'Patriot Rose Pink', and 'Tango Dark Red' were received from commercial suppliers (Dümmen Orange, Columbus, OH; Syngenta Flowers, Gilroy, CA) on 28 Nov. 2016. A second replication of the experiment was conducted with liners started from unrooted cuttings received on 10 Jan. 2017 from the same suppliers. Unrooted cuttings were inserted into peat-perlite-vermiculite plugs enclosed in a cellulose nonwoven net (26-count cell strips, Oasis ${ }^{\circledR}$ and Fertiss ${ }^{\circledR}$ Plant Propagation Systems; plug size: $3 \times 4 \mathrm{~cm}$, round; Smithers-Oasis, Kent, OH). Cuttings were placed in a glass-glazed greenhouse (North Carolina State University, Raleigh, NC) maintained at $24 \pm 2{ }^{\circ} \mathrm{C}$ during the day and $18 \pm$ $2{ }^{\circ} \mathrm{C}$ at night with a natural photoperiod of $\approx 9 \mathrm{~h}$ and $50 \mathrm{~min}$ for the first replication and $10 \mathrm{~h}$ for the second replication, with a daily light integral of 5 to $10 \mathrm{~mol} \cdot \mathrm{m}^{-2} \cdot \mathrm{d}^{-1}$. An automatic mist system operated every $8 \mathrm{~min}$ for $6 \mathrm{~s}$. After $24 \mathrm{~h}$, the mist interval was extended to once every $10 \mathrm{~min}$ for $6 \mathrm{~s}$. When roots were visually observed at the cutting base, supplemental irrigation was applied by hand watering for 1 week. Liners were removed from the mist 1 week after root initiation, hand watered daily, and alternated between two water-soluble fertilizers [15.0N0P-12.5K (Jack's Dark Weather; JR Peters, Allentown, PA) and $20 \mathrm{~N}-$ 6.7P-16.6K (General Purpose; JR Peters)] with $150 \mathrm{mg} \cdot \mathrm{L}^{-1}$ nitrogen until the experiment was initiated. The total propagation time was 5 weeks. Flowers and yellow or dead leaves were removed before initiating the shipping experiment.

Pathogen culture. Cultures of Botrytis cinerea were started from a conidial stock (obtained from $M$. Benson, North Carolina State University, Raleigh, NC) maintained at $-80{ }^{\circ} \mathrm{C}$ in a solution of $0.01 \%$ polysorbate 80 (Tween 80; Sigma-Aldrich, St. Louis, MO) and 15\% glycerol
(Sigma-Aldrich). Cultures were grown to sporulation in $15-\times 90-\mathrm{mm}$ polypropylene petri dishes containing 20 mL of oatmeal agar medium (Thermo Fisher Scientific, Lenexa, KS) prepared according to the manufacturer's directions. Culture dishes were not individually sealed; instead, they were placed in a clear plastic tub with wet paper towels that was then closed. Tubs were placed on a laboratory bench at room temperature. New cultures were started by inverting a sporulating plate over a new plate and tapping it to drop spores on the fresh medium.

When petri dishes were covered by dense, dark gray, sporulating mycelium $\approx 14 \mathrm{~d}$ after culture initiation, spores were harvested by pouring $\approx 15 \mathrm{~mL}$ of sterilized water containing $0.1 \%$ polysorbate 80 and $15 \%$ glycerol on the plate. A bent glass stirring rod was used to dislodge conidia by rubbing the culture for $\approx 5 \mathrm{~min}$ before pouring the spore suspension through five layers of sterilized cheesecloth to remove hyphae. The process was repeated twice on each petri dish. A Neubauer improved hemocytometer (LW Scientific, Lawrenceville, GA) was used to quantify the number of spores per milliliter for the resulting suspension. Suspensions were stored in $50-\mathrm{mL}$ polypropylene centrifuge tubes (Thermo Fisher Scientific) at $-80{ }^{\circ} \mathrm{C}$. On removal from storage, spore suspension stocks were diluted from stocks of $2 \times 10^{7}$ spores / $\mathrm{mL}$ with sterilized deionized water to reach their final concentration for inoculation.

INOCULATION APPLICATION. After 5 weeks of propagation, 240 uniform liners of each cultivar were selected. Liners were watered and foliage was allowed to dry for $2 \mathrm{~h}$ before treatment application. Sixty liners of each cultivar were randomly assigned to one of the four inoculation treatments: 1) dry control; 2) wet control containing $0.01 \%$ polysorbate 80 and $15 \%$ glycerol; 3 ) spore suspension of 2 $\times 10^{4}$ spores $/ \mathrm{mL}$ of $B$. cinerea spores containing $0.00001 \%$ polysorbate 80 and $0.015 \%$ glycerol (B4); and 4) spore suspension containing $2 \times 10^{6}$ spores $/ \mathrm{mL}$ of $B$. cinerea containing $0.001 \%$ polysorbate 80 and $1.5 \%$ glycerol (B6). The final 60 liners were left dry as a control. Tubes of spore suspensions were removed from storage at $-80{ }^{\circ} \mathrm{C} 2 \mathrm{~h}$ before liner inoculation 
and allowed to thaw in tap water at room temperature. The spore suspension concentration was adjusted to the desired inoculum levels with sterilized deionized water. Treatments were loaded into hand sprayers. While agitating, $\approx 45 \mathrm{~mL}$ was sprayed on all sides and tops of groups of 30 liners at one time.

The spore concentration used for inoculation was verified via the hemocytometer. Spore viability was determined by placing $100 \mu \mathrm{L}$ of the spore suspension on a petri plate of potato dextrose agar (Thermo Fisher Scientific). After $4 \mathrm{~h}$ of incubation at room temperature, 100 spores were counted under $100 \times$ magnification (TMS-F Inverted Microscope; Nikon Instruments, Melville, NY). Spores with a germination tube at least twice the diameter of the spores were considered viable, whereas spores without a germ tube were considered nonviable. The average spore viability in inoculation suspensions was $68 \% \pm$ $15 \%$ after five replications.

Temperature treatment. Liners from each inoculum treatment were placed in unwaxed cardboard boxes $(31-1 / 2 \times 21-1 / 2 \times 13-1 / 4$ inches) before being kept at the desired air temperatures. Cardboard boxes were then placed in one of two coolers with a constant air temperature (CAT) of $15{ }^{\circ} \mathrm{C}$ or a simulated air temperature (SAT) and subjected to a controlled 24 -h cycle of heating in a $10{ }^{\circ} \mathrm{C}$ chamber for variable times (Fig. 1). The fluctuating air temperatures of the SAT treatment were based on data obtained from the monitored liner shipments. Two boxes of liners were used for each temperature treatment, with each holding eight trays of liners so that each temperature had one tray of each inoculation treatment and six liners for each sampling duration.

EXPERIMENTAL DESIGN AND STATISTICAL ANALYSIS. A split-plot design was used, with air temperature as the whole plot and the cooler as the whole plot error term. The inoculation treatments, cultivar, and shipping duration were used as split-plot effects. Treatments were arranged as a $4 \times 4 \times 2$ factorial composed of four geranium cultivars, four inoculation treatments (dry control, wet control, $\mathrm{B} 4$, and B6), and two temperature treatments (CAT and SAT). Six liners were sampled from each cultivar by

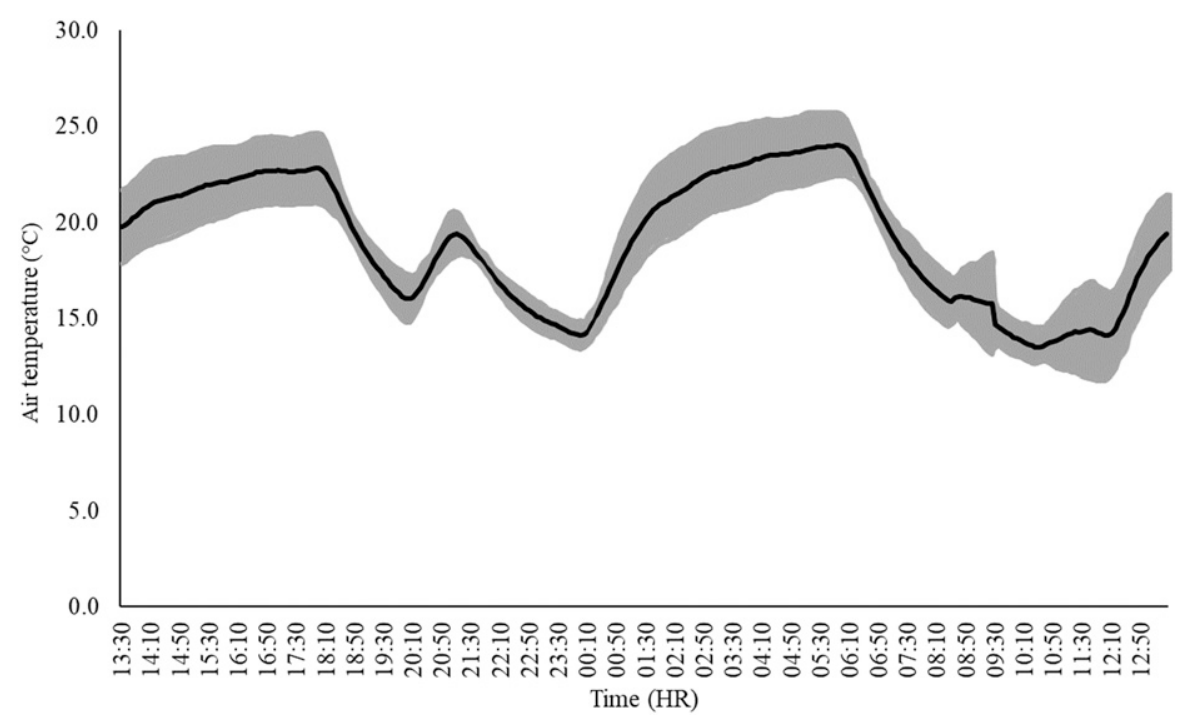

Fig. 1. Simulated temperature treatment with a controlled 24-h cycle of warming and $10^{\circ} \mathrm{C}$ chamber used for variable times based on air temperature (mean and standard deviation) for shipments of four commercial liners from a commercial grower in New Jersey to one location each in North Carolina, Oregon, Washington, and Wisconsin. $\left(1.8 \times{ }^{\circ} \mathrm{C}\right)+32={ }^{\circ} \mathrm{F}$.

using inoculation treatment combinations at $0,2,4,6$, and $8 \mathrm{~d}$ after initiation of air temperature treatments. A disease rating and leaf yellowing rating were recorded for each liner based on the visually affected area of all leaves of a given liner. A rating scale of 0 to 5 was used for the disease ratings (Fig. 2): $0=$ no symptoms; $1=<10 \%$ disease or 1 to 10 small lesions; $2=10 \%$ to $24 \%$ leaf necrosis or shoot necrosis; $3=25 \%$ to $50 \%$ leaf necrosis or $10 \%$ leaf necrosis with shoot necrosis; $4=51 \%$ to $75 \%$ leaf necrosis or $25 \%$ leaf necrosis with shoot necrosis; and $5=75 \%$ to $100 \%$ leaf necrosis with or without shoot necrosis. A scale of 0 to 6 was used for leaf yellowing ratings (Fig. 3): $0=$ no symptoms; $1=<10 \%$ marginal yellowing; $2=11 \%$ to $5 \%$ yellow; $3=26 \%$ to $50 \%$ yellow; $4=51 \%$ to $75 \%$ yellow; $5=51 \%$ to $75 \%$ yellow; and $6=$ dead or abscised.

Data were analyzed using SAS (version 9.4; SAS Institute, Cary, NC). Mean separation was determined using PROC MIXED and Tukey's Studentized procedures at $\alpha=0.05$. Median values of the six liners were used for each shipping duration, cultivar, and sampling day combination.

\section{Results and discussion}

AIR TEMPERATURE AND RELATIVE HUMIDITY OF COMMERCIAL SHIPMENTS. Liners were boxed between 0700 and
$1100 \mathrm{HR}$ at the commercial producer's site. Temperatures were increased initially or started high, most likely while boxes were waiting to be picked up by a delivery service (Fig. 4). Following pick-up, temperatures were decreased for $\approx 2 \mathrm{~h}$, followed by an increase for $\approx 6 \mathrm{~h}$ during the evening to 18 to $21{ }^{\circ} \mathrm{C}$. Night and morning temperatures decreased $\approx 2.8$ to $8.3{ }^{\circ} \mathrm{C}$. Temperatures then increased by $\approx 5.6$ to $8.3^{\circ} \mathrm{C}$ and continued to fluctuate until delivery. Some boxes experienced high temperatures after delivery, indicating that the receiving growers may not have placed the liners in adequately cooled locations. All liner shipments reached growers within $24 \mathrm{~h}$, except for the April Washington shipment. The grower who received the latter shipment did report leaf yellowing on leaf margins equal to a rating of 3 or 4 (Fig. $3)$. Liners in all other shipments remained green. Leaf yellowing in the Washington shipment may also have been accentuated by the high average temperature of $20^{\circ} \mathrm{C}$ compared with 18,17 , and $11^{\circ} \mathrm{C}$ in Wisconsin, North Carolina, and Oregon, respectively (Fig. 4A). The average temperature of the commercial liner shipments was $17^{\circ} \mathrm{C}$. The maximum and minimum temperatures for shipments in this study were 28 and $4{ }^{\circ} \mathrm{C}$, respectively.

Shipping and storage temperatures should be kept at 2 to $10{ }^{\circ} \mathrm{C}$ 


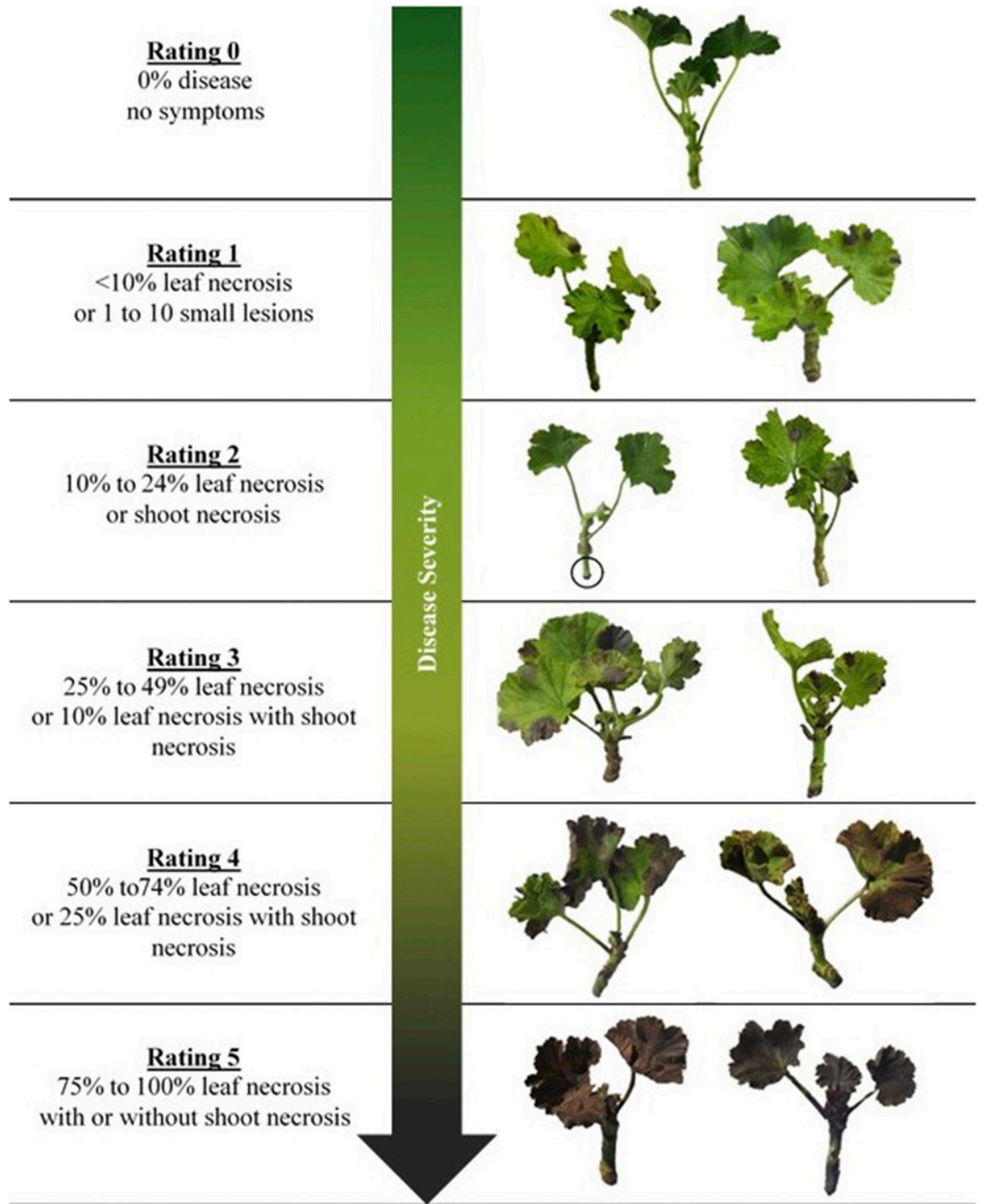

Fig. 2. Disease rating scale from 0 to 5 for gray mold on unrooted cuttings of geraniums based on the necrotic leaf area and stem necrosis.

(Faust et al., 2006, 2011). This air temperature range reduces respiration and ethylene production, and it is low enough to avoid $B$. cinerea sporulation and growth (Elad et al., 2007; Sirjusingh and Sutton, 1996). If delays occur during transport, then temperature variability and high average air temperatures in the recorded shipments could result in disease problems during commercial liner shipments. Rooting stations typically avoid shipping when temperatures exceed or are below the recommended ranges to avoid freezing and heat stress that may promote postharvest stress (T. Gunther, personal communication), but this is not always possible. Shipment air temperatures are generally influenced by the environment; the destination and time of year are important factors that determine the environment. The air temperature of the shipment to Oregon in December continued to decrease after packing, whereas the air temperatures of the shipments sent to Washington, Wisconsin, and North Carolina were higher during spring and fall months. Even though North Carolina is a more southern state closer to the equator than Wisconsin, the air temperatures were very similar for the two shipments sent in October.

When liners were boxed, $\mathrm{RH}$ increased quickly (Fig. 4B). After 3 $\mathrm{h}, \mathrm{RH}$ increased an average of $23.5 \%$ for all shipments. However, all shipments began at different $\mathrm{RH}$ levels and required varying amounts of time, from 27 to $329 \mathrm{~min}$, to reach $90 \%$ RH. The time required for packing or the time of year when shipments were sent may have affected RH and the rate of its increase. In all cases, liners were watered a minimum of $24 \mathrm{~h}$ before shipping, packed with dry leaves, and subjected to air temperatures between 12 and $19^{\circ} \mathrm{C}$ at the time of packing. For all shipments, RH stayed high and had small fluctuations while in transit. The average, maximum, and minimum $\mathrm{RH}$ levels were $91 \%, 96 \%$, and $56 \%$, respectively. High RH (80\% to $95 \%)$ is beneficial for plant materials in storage to reduce water use and loss and to keep them hydrated and turgid (Faust et al., 2006); however, it can also promote conditions conducive to fungal growth. Air temperatures and RH needed for disease development were present during shipping. However, no disease was reported, which may indicate that cultural practices and disease control at the rooting station were sufficient to avoid disease development during 2 to $3 \mathrm{~d}$ of shipping.

Disease AND LEAF Yellowing DURING SIMULATED SHIPPING. Disease ratings did not differ between the two air temperature treatments (CAT and SAT). There was a significant twoway interaction $(P<0.0001)$ for the disease ratings between shipping duration and inoculation treatment (Fig. 5). After $2 \mathrm{~d}$, the dry control had lower levels of disease than the carrier solution, B4, and B6 treatments (Fig. 5), which resulted in the development of a few small lesions. After day 2, liners treated with the carrier solution had higher disease ratings than all other treatments. Liners treated with the carrier solution were noticeably wetter than those treated by the other treatments by day 4 , which may have been caused by the higher concentration of glycerol and polysorbate 80 compared with the spore suspension sprays. Spore suspension sprays only contained glycerol and polysorbate 80 from frozen spore stocks used to create the diluted $10^{4}$ and $10^{6}$ spore suspensions.

Although $\mathrm{RH}$ was more than $80 \%$ until day 7 for both temperature treatments (data not shown), leaves treated with B4 and B6 were dry within 2 to $4 \mathrm{~d}$. At $4 \mathrm{~d}$ after treatment, $\mathrm{RH}$ decreased for both temperature treatments, which corresponded with the visual dryness and feel of the liner 


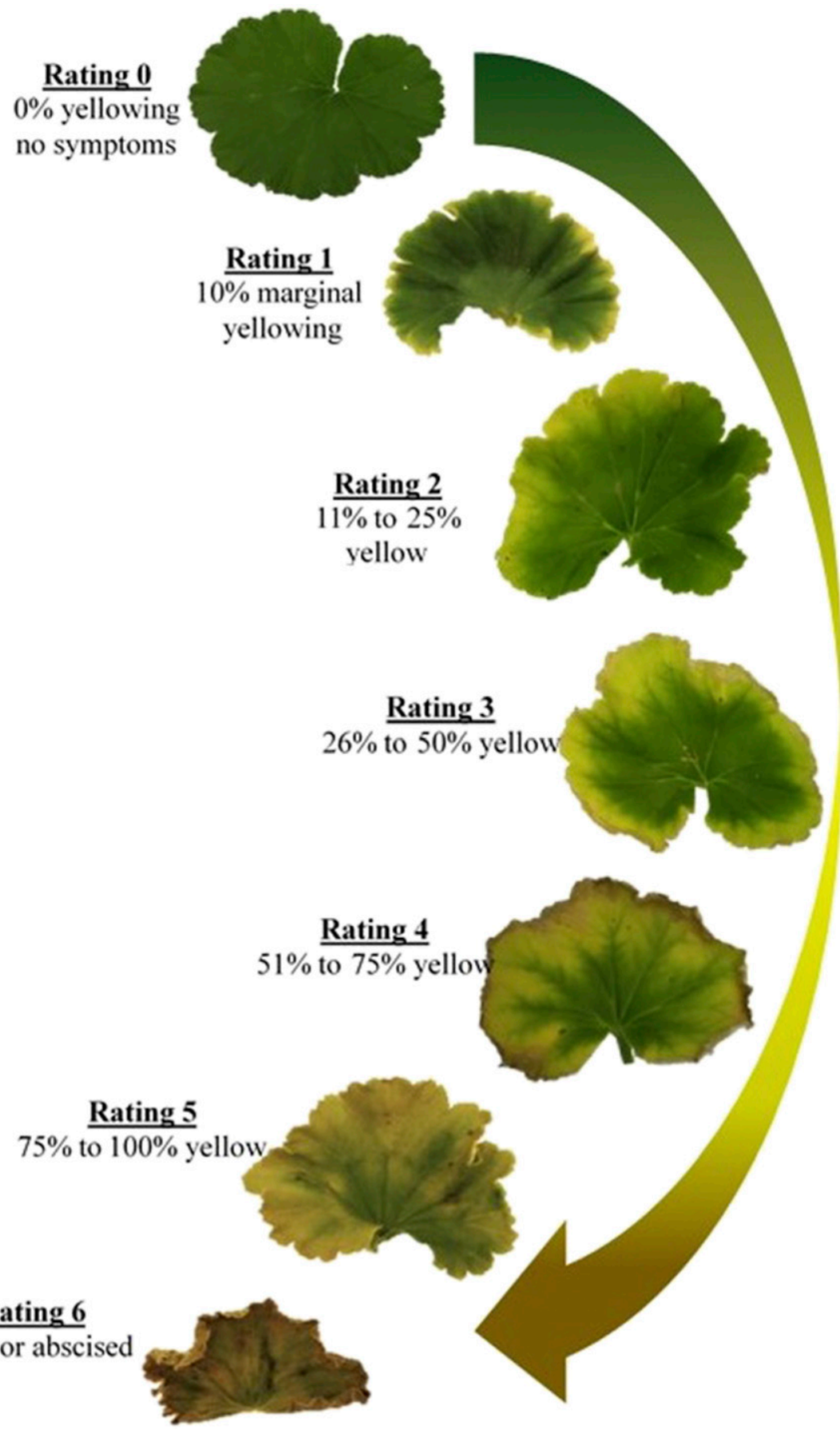

Fig. 3. Leaf yellowing rating scale from 0 to 6 for leaves of unrooted geranium cuttings.

root balls. The measured decrease in $\mathrm{RH}$ and observable lack of water content in root balls did not slow gray mold development. Moreover, the lack of moisture may have increased plant stress and allowed further colonization of the leaf tissue.

The two different spore concentrations of $B$. cinerea resulted in similar disease ratings during the shipping durations. Both B4 and B6 resulted in liners were sufficient to initiate disease. Given the proper environmental conditions and present inoculum, gray mold could occur in commercial shipments. However, unless the shipping time exceeds $2 \mathrm{~d}$, the amount of disease may not be a concern for growers. No fungicides were sprayed during liner production for this experiment; therefore, proper cultural practices and fungicide use could mitigate Botrytis diseases during normal shipping durations of liners. Cultivars had significantly different disease ratings $(P=0.016)$. Only 'Tango Dark Red' differed from 'Patriot Rose Pink', with average ratings of 0.8 and 1.0 , respectively. These average ratings across median values for each treatment combination would be visually indistinguishable in a commercial setting. If disease is observed, then growers will discard infected materials.

There was a significant interaction between the CAT and SAT treatments for leaf yellowing ratings $(P<$ $0.0001)$. Both treatments significantly increased leaf yellowing over time (Fig. 6). By day 4, the SAT treatment caused significantly higher leaf yellowing ratings until day 8 , when treatments did not differ. $\mathrm{Al}$ though the preferred shipping and storage temperatures are between 2 to $10^{\circ} \mathrm{C}$ (Faust et al., 2006), in this experiment an average constant temperature of $15^{\circ} \mathrm{C}$ was sufficient to minimize leaf yellowing after $2 \mathrm{~d}$ compared with the variable temperatures of the SAT treatment. Based on the aforementioned commercial air temperature logs, large temperature variations occur during liner transport and may accentuate leaf yellowing on geranium liners.

'Patriot Rose Pink' was the most susceptible to leaf yellowing $(P<$ $0.0001)$, with a rating of 1.6. This agrees with the industry observing Patriot Rose Pink as a poor shipping cultivar (A. Hammer, personal communication). 'Americana Red', 'Patriot Bright Red', and 'Tango Dark Red' did not differ from each other, and all had a rating of 1.3. Liners of the four cultivars visually differed in habit and leaf size, which indicated that dehydration and potential area for infection may have been factors that affected responses. 'Americana Red', 'Patriot Bright Red', and 'Tango Dark Red' had larger leaf areas and were larger liners overall, 

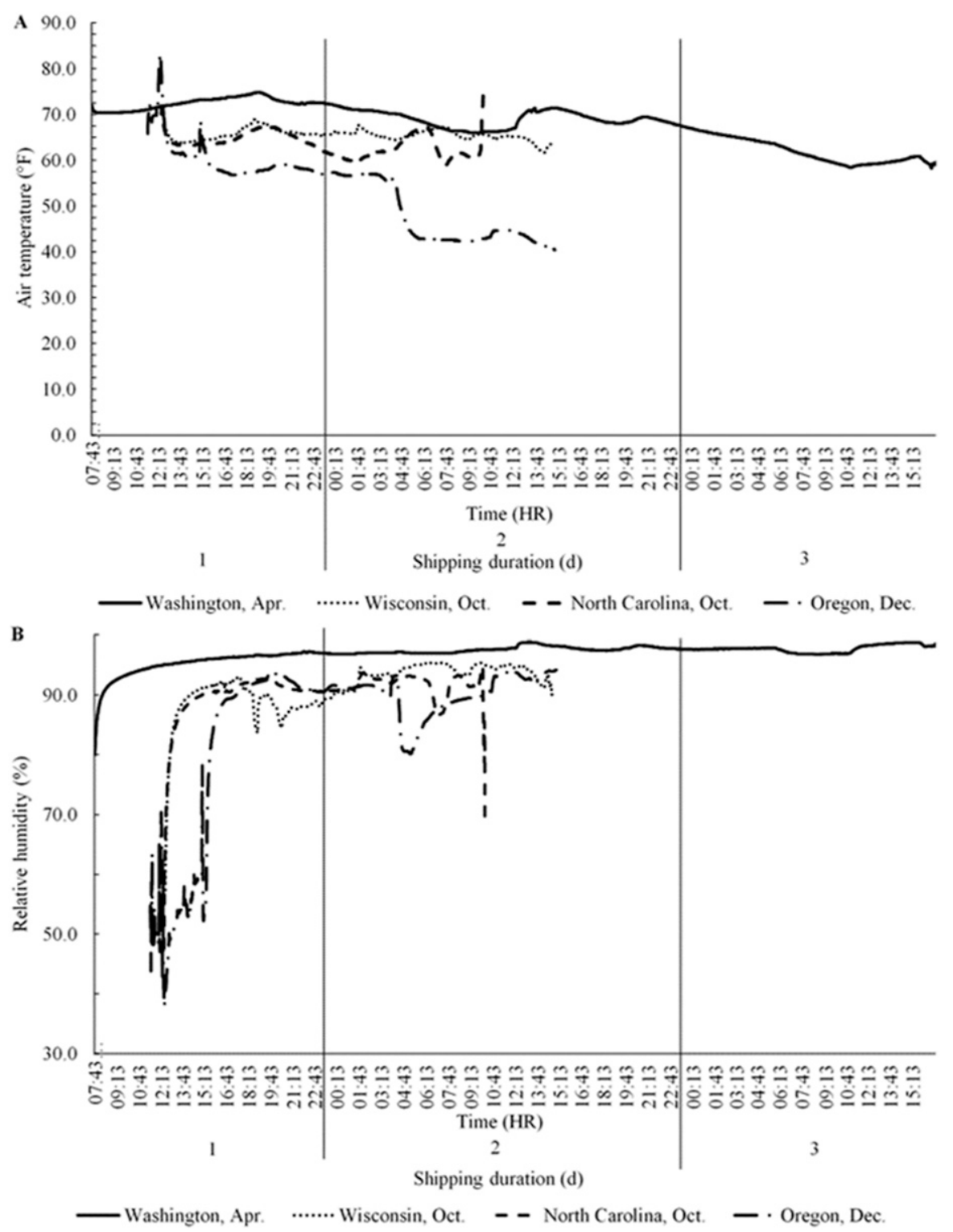

Fig. 4. Air temperatures (A) and relative humidity (B) of geranium liner shipments were recorded by a grower in New Jersey and commercial growers in the following states: Washington (26 Apr. 2016), Wisconsin (11 Oct. 2016), North Carolina (11 Oct. 2016), and Oregon (6 Dec. 2016). Liners were irrigated 24 h before boxing. $\left(1.8 \times{ }^{\circ} \mathrm{C}\right)+32={ }^{\circ} \mathrm{F}$.

whereas 'Patriot Rose Pink' was shorter and had smaller leaves. Patriot Rose Pink was a consistently slowgrowing cultivar that produced smaller liners during both replications of the experiment compared with the other three cultivars.

Proper conditions for disease development were observed in commercial liner shipments. However, in this experiment, simulating those conditions revealed that disease development is minimal when the shipping duration is short and the leaf surfaces are dry. Cutting producers and fungicide-resistant populations continue to grow (Fillinger and Walker, 2016), other methods of control such as ultraviolet $\mathrm{C}$ pulses (Darras et al., 2015) and increased secondary metabolite production like mannitol dehydrogenase have shown positive results regarding increasing geranium resistance (Williamson et al., 2013). It may take some time to implement these methods in the production system, and they will need to be considered in the price of unrooted cuttings and liners. Even when using the best control, disease may occur after shipping. It will be important to determine if stress incurred during shipping along with small amounts of disease are enough to reduce plant quality when finishing plants.

In contrast to disease development, leaf yellowing occurred with both temperature treatments after 2 d. Even though commercial shipment durations are fewer than $2 \mathrm{~d}$, minor leaf yellowing can reduce visual quality and add extra labor costs to remove leaves and prevent disease development. Antiethylene products such as 1-methylcyclopropene (1MCP) may be an option as a preshipping treatment to ensure green leaf tissue (Cameron and Reid, 2001). If tissue remains green, then there is a lower chance that leaves will become infected. However, higher temperatures $\left(\geq 20^{\circ} \mathrm{C}\right)$ reduce the effectiveness of $1-M C P$ and can have adverse effects on root development of cuttings (Kadner and Druege, 2004). Another option for reducing yellowing is a combination of benzyladenine and gibberellic acid, which has been used on unrooted cuttings (Currey et al., 2013; Faust et al., 2011). Many floriculture products are shipped in cardboard containers. These containers retain humidity, slow the dispersal of ethylene, and are an inadequate buffer for temperature fluctuations. Modified atmosphere packaging has been used in conjunction with a variety of horticulture products to increase shelf life, but species react differently to oxygen and carbon dioxide levels, and ethylene concentrations may increase to damaging levels (Crawford, 2013). Methods to ensure plant quality throughout shipping remain an important and complex issue for the industry. 


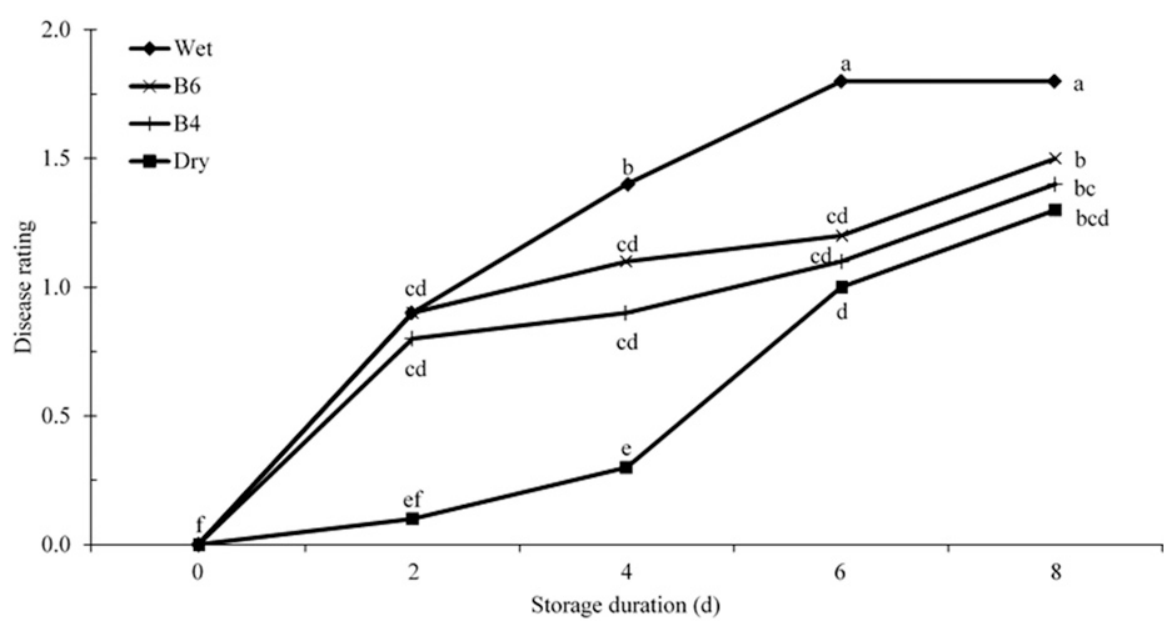

Fig. 5. Average disease ratings for temperature treatments of geranium liners based on the interaction of shipping duration and spray treatment $(P<0.0001)$ : dry control (Dry); wet control with $0.01 \%$ polysorbate 80 and $15 \%$ glycerol (Wet); Botrytis spore suspension $2 \times 10^{4}$ spores $/ \mathrm{mL}$ containing $0.0001 \%$ polysorbate 80 and $0.015 \%$ glycerol (B4); and Botrytis spore suspension $2 \times 10^{6}$ spores $/ \mathrm{mL}$ containing $0.001 \%$ polysorbate 80 and $1.5 \%$ glycerol (B6). Disease ratings were determined by the following severity scale: $0=0 \%$ disease to $5=75 \%$ to $100 \%$ leaf necrosis with or without shoot necrosis. Means were calculated by averaging the median values of the six liners from each temperature treatment $(n=2)$. Means followed by the same letter are not significantly different according to Tukey's Studentized range test procedure at $\alpha=0.05 ; 1$ spore $/ \mathrm{mL}=29.5735$ spores $/ \mathrm{fl} \mathrm{oz}$.

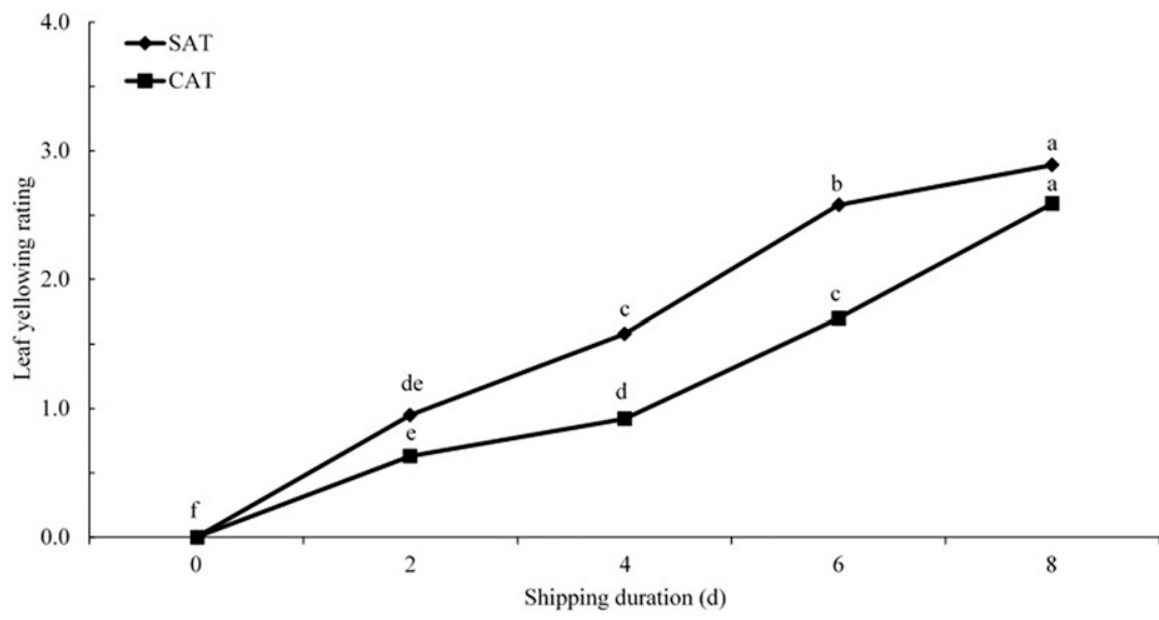

Fig. 6. Average leaf yellowing ratings across inoculation treatments for geranium liners based on the interaction of shipping duration (d) and air temperature treatment $(P<0.0001)$. The constant air temperature treatment $(\mathrm{CAT})$ involved a temperature of $15^{\circ} \mathrm{C}$. Simulated air temperature treatment (SAT) involved a controlled $24-\mathrm{h}$ cycle of warming at $10^{\circ} \mathrm{C}$. A chamber was used for variable times based on air temperatures of commercial liner shipments. Leaf yellowing was rated using the following scale: $0=0 \%$ yellowing to $6=$ dead or abscised. Means were calculated by averaging the median values of the six liners used for each inoculation treatment $(n=4)$. Means followed by the same letter are not significantly different according to Tukey's Studentized range test procedure at $\alpha=0.05$. $\left(1.8 \times{ }^{\circ} \mathrm{C}\right)+32={ }^{\circ} \mathrm{F}$.

\section{Conclusion}

This study reemphasized cleanliness and cultural practices before shipping to avoid and combat Botrytis diseases. Plant materials shipped wet lead to disease during production and higher input costs for growers. Using precooling or forced air cooling along with commonly used ice packs could reduce and maintain box temperatures during storage and mitigate disease and leaf yellowing. Along with previous works regarding geraniums, this study supports the conclusion that cultivar resistance will do little to mitigate Botrytis diseases. Researching methods of controlling air temperature during shipping, strengthening the plant's resistance to environmental stress, researching chemical and bio-control options, and tracking shipment environments in real time would allow the industry to better protect valuable products, forecast potential issues, and plan for damaged shipments before they reach customers.

\section{Literature cited}

Arteca, R.N., C.D. Schlagnhaufer, T.W. Wang, and J.M. Arteca. 1996. Physiological, biochemical, and molecular changes in Pelargonium cuttings subjected to short-term storage conditions. J. Amer. Soc. Hort. Sci. 121:1063-1068.

Cameron, A.C. and M.S. Reid. 2001. 1-MCP blocks ethylene-induced petal abscission of Pelargonium peltatum but the effect is transient. Postharvest Biol. Technol. 22:169-177.

Crawford, B.D. 2013. Increasing postharvest quality and propagation success of plant cuttings. MS Thesis, North Carolina State Univ., Raleigh.

Currey, C.J., R.G. Lopez, V.K. Rapaka, and J.E. Faust. 2013. Exogenous applications of benzyladenine and gibberellic acid inhibit lower-leaf senescence of geraniums during propagation. HortScience 48:1352-1357.

Darras, A.I., I. Bali, and E. Argyropoulou. 2015. Disease resistance and growth responses in Pelargonium $\times$ hortorum plants to brief pulses of UV-C irradiation. Scientia Hort. 181:95-101.

Elad, Y., B. Williamson, P. Tudzynski, and N. Delen. 2007. Botrytis: Biology, pathology and control. Springer, Dordrecht, The Netherlands.

Faust, J.E., A.L. Einfield, A.M. Blankenship, and J.M. Dole. 2006. Postharvest, p. 145152. In: J.M. Dole and J.L. Gibson (eds.). Cutting propagation. Ball Publ., Batavia IL.

Faust, J.E., V. Rapaka, and L. Kelly. 2011. Geranium leaf yellowing: Causes and solutions. Amer. Floral Endowment Spec. Res. Rpt. 451

Fillinger, S. and A. Walker. 2016. Chemical control and resistance management of 


\section{Research Reports}

Botrytis diseases, p. 189-216. In: S. Fillinger and Y. Elad (eds.). Botrytis - The fungus, the pathogen and its management in agricultural systems. Springer Intl. Publ., Cham, Switzerland.

Gibson, J.L. and J.M. Dole. 2006. Cutting propagation. Ball Publ., Batavia IL.

Hausbeck, M.K. 1990. The epidemiology of Botrytis cinerea Pers. on the geranium (Pelargonium $\times$ hortorum L.H. Bailey). PhD thesis, Pennsylvania. State Univ., University Park.

Kadner, R. and U. Druege. 2004. Role of ethylene action in ethylene production and poststorage leaf senescence and survival of pelargonium cuttings. Plant Growth Regulat. 43:187-196.
Purer, O. and S. Mayak. 1988. Pelargonium cuttings - Effects of growth regulators. Acta Hort. 261:347-354.

Rapaka, V.K., J.E. Faust, J.M. Dole, and E.S. Runkle. 2008. Endogenous carbohydrate status affects postharvest ethylene sensitivity in relation to leaf senescence and adventitious root formation in pelargonium cuttings. Postharvest Biol. Technol. 48:272-282.

Sirjusingh, C. and J.C. Sutton. 1996. Effects of wetness duration and temperature on infection of geranium by Botrytis cinerea. Plant Dis. 80:160-165.

Uchneat, M.S., A. Zhigilei, and R. Craig. 1999. Differential response to foliar infection with Botrytis cinerea within the genus Pelargonium. J. Amer. Soc. Hort. Sci. 124:76-80.
U.S. Department of Agriculture. 2016. 2015 Floriculture crops summary. Natl. Agr. Stat. Serv., U.S. Dept. Agr., Washington, DC.

Williams, K.A. 2006. Propagation industry, p. 17-29. In: J.M. Dole and J.L. Gibson (eds). Cutting propagation. Ball Publ., Batavia, IL.

Williamson, J.D., A. Desia, S.F. Krasnyanski, W. Guo, T. Ngyuyen, H.A. Olson, J.M. Dole, and G.C. Allen. 2013. Overexpression of mannitol dehydrogenase in zonal geranium confers increased resistance to the mannitol secreting fungal pathogen Botrytis cinerea. Plant Cell Tissue Organ Cult. 115:367-375. 